\title{
Efeito da gordura protegida sobre a produção e composição do leite em ovelhas da raça Bergamácia ${ }^{1}$
}

\section{Monalissa de Melo Stradiotto ${ }^{2}$, Edson Ramos de Siqueira ${ }^{3}$, Rodrigo Martins de Souza Emediato $^{2}$, Sirlei Aparecida Maestá ${ }^{2}$, Marcela Buosi Martins ${ }^{2}$}

\author{
1 Projeto financiado pela FAPESP. \\ 2 Departamento de Produção Animal da FMVZ - UNESP - Botucatu - SP. \\ ${ }^{3}$ FMVZ - UNESP - Botucatu - SP. Pesquisador do CNPq.
}

RESUMO - Objetivou-se avaliar o efeito da gordura protegida sobre a produção e composição do leite em ovelhas da raça Bergamácia. Utilizaram-se 77 ovelhas distribuídas, por ordem de parição e idade, em duas dietas: uma composta de silagem de milho e concentrado; e outra com gordura protegida (35 g/ovelha/dia) no concentrado. As dietas foram isoenergéticas e isoproteicas e continham 70\% NDT e 16\% PB com base na matéria seca. Os cordeiros permaneceram com suas mães até os 45 dias de idade, quando foram desmamados. Quarenta e oito horas após o parto, deu-se início a ordenha realizada uma vez ao dia, às $7 \mathrm{~h}$, para mensuração diária da produção de leite durante 60 dias. Amostras de leite foram coletadas semanalmente para análise da composição centesimal e do teor de caseína. A dieta com gordura protegida promoveu maior produção média diária de leite após a desmama (0,531 vs $0,489 \mathrm{~kg} /$ dia), entretanto, a produção total do período não diferiu entre controle e com gordura protegida ( 0,453 vs $0,468 \mathrm{~kg} /$ dia, respectivamente). Não foi observada influência das dietas sobre os teores de gordura do leite até a sexta semana de lactação. As diferenças ocorreram apenas após a desmama. Os teores de alfa e beta caseínas diferiram entre os grupos controle e gordura protegida (31,73 vs 18,56 Kda para alfa-caseína e 32,67 vs 26,44 Kda para beta-caseína, respectivamente). A adição de gordura protegida na dieta não altera a produção nem a composição centesimal do leite até a desmama.

Palavras-chave: lipídio, ordenha, ovino

\section{Effect of bypass fat on milk production and composition in Bergamasca ewes}

\begin{abstract}
The aim of this work was to evaluate the effect of bypass fat on milk production and composition in Bergamasca ewes. It was used 77 ewes which were distributed by parity and age orders in two groups: control diet (C): corn silage and concentrate; and bypass fat diet (GP): corn silage + concentrated + bypass fat (35 g/ewe/day) added in the concentrate. Diets were isoenergetic and isonitrogenous with $70 \%$ of total digestible nutrients and $16 \%$ of crude protein on dry matter basis. Lambs were kept to their mothers until 45 days of age, when they were weaned. Forty-eight hours after lambing, ewes were milked once a day at 7:00 a.m. for daily measurement of milk production during 60 days. Milk samples were weekly collected for analysis of centesimal composition and casein content. The bypass fat diet presented higher daily average milk production after weaning ( $0.531 \mathrm{vs} 0.489 \mathrm{~kg} /$ day $)$, however, average milk production of the whole experimental period was not different between control and bypass diet ( $0.453 \mathrm{vs} 0.468 \mathrm{~kg} / \mathrm{day}$, respectively). No differences were observed among control and bypass diets for milk fat content until the 6th week of lactation; they were observed only after weaning. Alpha $(\alpha)$ and beta $(\beta)$ casein content presented differences between control and bypass diet groups (31.73 vs $18.56 \mathrm{Kda}$ for alpha casein and 32.67 vs $26.44 \mathrm{Kda}$ for beta casein, respectively). Bypass fat added to diet do not change milk production and centesimal composition until weaning.
\end{abstract}

Key Words: lipid, milking, sheep

\section{Introdução}

No Brasil, a ovinocultura de leite ainda é uma atividade recente com pouca expressão de mercado. Segundo Sá et al. (2005), mesmo em países cuja produção de leite ovino é uma tradição, há deficiências de novas tecnologias e trabalhos científicos ligados à atividade.

Durante a ordenha, o leite alveolar, rico em gordura (Labussière, 1969; Mckusic et al., 2002), pode ser ejetado após a contração das células mioepiteliais que circundam os alvéolos. Este processo é mediado pela ocitocina, 
hormônio pituritário liberado na corrente sanguínea após um reflexo neural (Labussière et al., 1969; Bruckmaier et al., 1997), induzido por um estímulo externo, que pode ser o começo da ordenha ou a sucção do cordeiro ou apenas a presença do cordeiro ou ordenhador usual, como também o som da pulsação do vácuo da ordenhadeira (Casu et al., 2008).

Sabe-se que o principal nutriente que limita a produção de leite é a energia. Maiores exigências são observadas em ovelhas nas primeiras oito semanas de lactação, com valores de até 8,5 Mcal de energia digestível por animal por dia (NRC, 1985).

Nos últimos anos, têm-se verificado a possibilidade de adicionar à dieta uma quantidade de gordura protegida no rúmen mas utilizada no intestino e diretamente convertida em triglicerídeos pelo animal (Jenkins \& Palmquist, 1984). A inclusão de lipídeos insolúveis, além de aumentar a densidade calórica da dieta sem comprometer a degradação da fibra, possibilita maior ingestão e melhor eficiência de utilização de energia, permitindo absorção e metabolismo de substrato com melhor relação entre nutrientes lipogênicos e glicogênicos (Kronfeld et al., 1980).

Objetivou-se com este trabalho verificar o efeito da gordura protegida na produção e composição do leite em ovelhas da raça Bergamácia.

\section{Material e Métodos}

O experimento foi conduzido na Unidade de Pesquisa em Produção de Leite de Ovelha da Faculdade de Medicina Veterinária e Zootecnia da Universidade Estadual Paulista (UNESP), Campus de Botucatu, São Paulo, durante os meses de julho a outubro de 2005. A cidade de Botucatu está situada na latitude $22^{\circ} 52^{\prime} 47^{\prime \prime} \mathrm{S}$, longitude $48^{\circ} 25^{\prime} 12^{\prime \prime} \mathrm{W}$ e altitude de $810 \mathrm{~m}$ e, no período experimental, apresentou temperatura média de $18,32^{\circ} \mathrm{C}$, umidade relativa do ar de 51,07\% e precipitação de 72,33 mm.

Utilizaram-se 77 ovelhas da raça Bergamácia distribuídas aleatoriamente por idade e ordem de parição dentro do ano, duas dietas: controle $(n=37)$ e Gordura Protegida $(n=40)$.

Durante a gestação, os animais foram mantidos em pastagem de Panicum maximum cv. Tanzânia. Iniciou-se um período de adaptação de 20 dias antes da parição, com as seguintes dietas experimentais: silagem de milho (Zea mays) concentrado composto de: milho moído, farelo de soja, polpa cítrica, farelo de algodão, refinazil (glúten de milho), ureia, calcário, sal mineral e 35 g/ovelha/dia de gordura protegida (Megalac- $\mathrm{E}^{\circledR}$ - Church and Dwight Co.,
Inc.) (sendo adição de 3,5\% de gordura protegida, para um grupo), e foram vacinadas contra as Clostridioses (Clostridium chauvoei, C. septicum, C. perfringens, C. novyi, C. sordellii e C. tetani - Sintoxan Polivalente ${ }^{\circledR}$ Merial) no terço final da gestação.

As ovelhas receberam concentrado durante todo o período experimental, $0,300 \mathrm{~kg}$ durante a ordenha e $0,700 \mathrm{~kg}$ misturado à silagem de milho, em duas refeições ao dia, às 7 e às $17 \mathrm{~h}$, totalizando $1 \mathrm{~kg}$ de concentrado/dia. A oferta de silagem foi de $1 \mathrm{~kg}$ MS/ovelha/dia, com relação volumoso: concentrado 50:50.

As dietas foram isoenergéticas e isoproteicas e continham 16\% PB e 70\% NDT, com base na matéria seca (Tabela 1). Os animais receberam sal mineral específico ad libitum (Núcleo Maxiovinos $40^{\circledR}$ - Maxi Nutrição Mineral Ltda) durante todo o período experimental.

Para ambos os grupos, adotou-se o sistema misto de produção de leite, mantendo os cordeiros com suas mães na pastagem durante o dia eseparando às $17 \mathrm{~h}$, quando receberam concentrado balanceado de acordo com NRC (1985) até a desmama (45 dias de idade). Após a ordenha, os cordeiros retornavam às suas mães. As ovelhas, a partir de 48 horas pós-parto, foram ordenhadas mecanicamente uma vez ao dia, às $7 \mathrm{~h}$ e a produção de leite foi mensurada diariamente durante 60 dias. As análises estatísticas foram feitas apenas para o leite mecanicamente ordenhado (leite comercial), desconsiderando o leite mamado pelos cordeiros.

Utilizou-se sala de ordenha com plataforma e capacidade para dez ovelhas, com ordenhadeira mecânica (Westfalia Tipo RO) com quatro conjuntos de ordenha e linha de leite baixa, taxa de pulsação de 120 pulsos/min e nível de vácuo de $36 \mathrm{KPa}$. Diariamente, antes de iniciar a ordenha, os úberes foram desinfetados com solução de iodo glicerinado e secos com papel-toalha.

A ordem de ordenha foi alternada entre os grupos controle e gordura protegida, assim, o primeiro a ser ordenhado em um dia era o segundo no dia seguinte, para evitar influência do período do dia na produção de leite.

Uma vez por semana foram coletadas amostras de leite de todas as ovelhas para análise da composição centesimal; enquanto, para o teor de caseína, utilizaram-se amostras de 20 ovelhas de cada grupo (controle e gordura protegida), escolhidas de forma homogênea (idade, número de cordeiros nascidos), sempre as mesmas. As concentrações de proteína, gordura, lactose e sólidos totais foram determinadas no equipamento infravermelho Bentley 2000 (Bentley Instruments, INC. Chaska-MN-USA). A determinação do teor de caseína foi realizada pela técnica de eletroforese em gradiente em gel de poliacrilamida vertical 
Tabela 1 - Composição dos ingredientes e do concentrado utilizados nas dietas

\begin{tabular}{|c|c|c|c|c|c|c|c|c|}
\hline \multirow[b]{2}{*}{ Nutriente } & \multicolumn{6}{|c|}{$\begin{array}{c}\text { Ingrediente } \\
(\% \mathrm{MS})\end{array}$} & \multicolumn{2}{|c|}{$\begin{array}{c}\text { Concentrado } \\
\text { (\% MS) }\end{array}$} \\
\hline & Refinazil & $\begin{array}{l}\text { Milho } \\
\text { moído }\end{array}$ & $\begin{array}{l}\text { Farelo } \\
\text { de soja }\end{array}$ & $\begin{array}{l}\text { Polpa } \\
\text { cítrica }\end{array}$ & $\begin{array}{c}\text { Farelo de } \\
\text { algodão }\end{array}$ & $\begin{array}{l}\text { Silagem } \\
\text { de milho }\end{array}$ & Controle & $\begin{array}{c}\text { Gordura } \\
\text { protegida }\end{array}$ \\
\hline Matéria seca & 87,91 & 87,12 & 87,51 & 88,98 & 90,85 & 33,52 & 88,00 & 88,65 \\
\hline Proteína bruta & 20,70 & 10,43 & 54,65 & 6,81 & 41,00 & 7,59 & 24,94 & 24,51 \\
\hline Extrato etéreo & 4,24 & 6,78 & 0,89 & 4,22 & 5,54 & 2,41 & 4,16 & 4,36 \\
\hline Matéria mineral & 4,36 & 2,24 & 6,97 & 6,38 & 6,40 & 3,81 & 9,00 & 9,78 \\
\hline Nutrientes digestíveis totais & 92,31 & 80,75 & 89,35 & 64,30 & 95,07 & 64,18 & 76,63 & 78,76 \\
\hline Carboidratos não-fibrosos & 6,79 & 48,56 & 17,40 & 42,70 & 1,35 & 13,47 & 20,75 & 22,27 \\
\hline Fibra em detergente neutro & 50,85 & 25,40 & 14,05 & 24,24 & 33,52 & 47,39 & 28,62 & 26,91 \\
\hline Fibra em detergente ácido & 16,22 & 10,10 & 9,84 & 22,20 & 22,55 & 28,95 & 18,92 & 20,38 \\
\hline
\end{tabular}

em dodecil sulfato de sódio (SDS-PAGE), alcalina (pH 8,3), em sistema de tampões descontínuos, descrita por Hames \& Rickwood (1990) com algumas modificações descritas por Ramos (1992). Para identificação das frações das caseínas do leite, foram utilizados géis de empilhamento na concentração de $4 \%$ e géis de separação na concentração de $10 \%$. Os geis foram analisados empregando-se o Image Master VDS (Pharmacia). Os pesos moleculares das bandas foram estimados mediante a interpolação das bandas, tendo como referência as mobilidades relativas das bandas proteicas do padrão de pesos moleculares empregado.

Os cordeiros foram vacinados contra as Clostridioses na ocasião da desmama.

Os dados experimentais foram analisados como parcelas subdivididas, em delineamento inteiramente casualizado como medidas repetidas, por meio de análise de variância e teste de médias $(\mathrm{P}<0,05)$, utilizando-se o programa SAEG 9.0 (UFV, 1997).

As correlações entre características foram calculadas corrigindo-se os dados para efeito de grupo (controle e gordura protegida) e testadas pelo teste $\mathrm{t}(\mathrm{P}<0,05)$ de acordo com Stell \& Torrie (1980).

\section{Resultados e Discussão}

Não houve diferença na produção de leite até a sétima semana de lactação entre os grupos alimentados com as dietas controle e com gordura protegida, provavelmente em virtude do sistema de produção utilizado, ou seja, a presença dos cordeiros com as mães levou à retenção de leite e, apesar de a desmama ter sido feita na sexta semana, seu efeito foi só percebido uma semana depois. Marnet \& Mckusick (2001) salientaram que o vínculo mãe-filho parece ser um forte regulador de secreção de oxitocina. A ejeção contínua do leite depende da presença de elevada concentração de oxitocina durante toda a ordenha e qualquer falha no processo de ejeção de leite pode interromper sua remoção (Bruckmaier \& Blum, 1998).
Marnet \& Negrão (2000) verificaram que a concentração plasmática de oxitocina foi maior quando houve amamentação dos cordeiros, em comparação à ordenha mecânica, fato atribuído não a uma ineficiência da glândula pituitária, mas a um efeito do comportamento materno, pelo qual a inibição do reflexo da ejeção do leite ocorre devido ao estresse e à vasoconstrição, ausente quando as ovelhas amamentam seus cordeiros. A dieta com gordura protegida resultou em maior produção média diária de leite em todo o período experimental $(0,468$ vs $0,453 \mathrm{~kg} / \mathrm{animal} / \mathrm{dia}$, respectivamente). Aprodução diária de leite diferiu apenas na $8^{\mathrm{a}}$ e $9^{\mathrm{a}}$ semanas de lactação.

O pico de lactação da ovelha ocorre em média entre a $2^{\underline{a}}$ e 4- a semanas de lactação (Church, 1984). Neste trabalho, com a desmama aos 45 dias, o efeito inibitório da presença do cordeiro sobre a produção de leite retardou o pico de produção de leite comercial para a 7a semana (após a desmama) e permitiu a expressão do potencial de produção das ovelhas somente neste período, prejudicando a produção total de leite comercial.

De acordo com Gargouri et al. (1995), mais leite comercial é produzido quando as ovelhas são ordenhadas duas vezes ao dia, ou no mínino uma vez e amamentam os cordeiros durante os primeiros 30 dias de lactação.

Após a desmama, o aumento médio diário foi de pouco mais de 100 g por ovelha (Tabela 2), o que não representa a capacidade máxima de produção de leite das ovelhas durante 24 horas, mas sua capacidade máxima de armazenamento, pois, com o fim do efeito negativo da presença do cordeiro sobre a produção de leite, a produção de leite comercial deveria ter aumentado mais no período pós- desmama, uma vez que os cordeiros mamam mais de 100 g de leite/dia. Da sexta para a sétima semana, as ovelhas alimentadas com a dieta controle aumentaram a produção em $103 \mathrm{~g}$ (de 0,451 para 0,554 g de leite/dia) e o ganho de peso em 115 g (de 0,448 para 0,563 g de leite/dia). Degen \& Benjamin (2003), observaram que cordeiros da raça Awassi ingeriram cerca de 1,3 litro de leite/dia ou 5,2 litros de 
leite/kg PV ganho. O fato de as ovelhas terem sido ordenhadas apenas uma vez ao dia pode ter influenciado a produção de leite após a desmama dos cordeiros (Tabela 2), com o possível aumento da pressão intramamária e a diminuição da secreção do leite, comuns no período pósdesmama.

O efeito da suplementação com gordura protegida foi observado por Chilliard \& Bocquier (1993), Caja \& Bocquier (2000) e Bocquier \& Caja (2001), que, após ampla revisão, verificaram que o uso da gordura protegida aumentou a produção de leite de vacas leiteiras, mas nem sempre aumentou a produção em cabras e ovelhas, no entanto, o inverso ocorreu com o teor de gordura do leite, que não apresentou diferença entre os grupos controle e gordura protegida $(\mathrm{P}>0,05)$, antes da desmama (semanas 1 a 6 ) (Tabela 3). Esperar-se-iam valores mais altos, porém a gordura permaneceu retida nos alvéolos, já que nesse sistema de produção o cordeiro era o estímulo para a liberação do leite, e não a ordenhadeira. De acordo com Labussière (1969), a distribuição da gordura do leite é de apenas $25 \%$ na fração cisternal e $75 \%$ na fração alveolar, a qual é retida quando ocorre alguma falha na ejeção do leite.

Os teores de gordura do leite mantiveram-se semelhantes durante todo o período em que as ovelhas amamentaram seus cordeiros, para ambos os grupos, controle e gordura protegida (3,5\% na dieta), e assim que os cordeiros foram desmamados, os teores de gordura das dietas com gordura protegida,diminuiram em relação ao grupo controle na $7 \underline{a}$ e $8^{\underline{a}}$ semana, mas na $9^{\underline{a}}$ voltaram a ser semelhantes, uma recuperação do teor de gordura do grupo com $3,5 \%$ de gordura protegida incorporado na dieta.

No período antes da desmama, como houve efeito da inibição da gordura do leite sobre a produção de leite até a 7a semana de lactação (Tabela 3), não foi possível visualizar o pico de lactação em ambos os grupos e, a partir da desmama, a produção de leite aumentou significativamente (Tabela 2), principalmente no grupo com a dieta com gordura protegida. Esta poderia ser uma resposta para a maior porcentagem de gordura no grupo com a dieta controle em comparação àquela com gordura protegida, pois, de acordo com Otto \& Sá (2001), há uma correlação negativa entre a produção e a composição do leite.

Embora não se tenha avaliado a produção e composição do leite além de 60 dias de lactação, tem-se observado na literatura que, com maiores períodos de lactação após a desmama do cordeiro, ocorre também expressivo aumento no teor de gordura do leite. Resultados similares foram encontrados por Mckusick et al. (1999), que avaliaram o sistema misto e de desmame precoce, com e sem suplementação de gordura protegida e encontraram teores de gordura no leite menores para as ovelhas do sistema misto, independentemente da suplementação, seguidas das ovelhas do grupo desmame precoce sem suplementação e maior para as do grupo desmame precoce com suplementação com valores de 2,51; 5,28 e 6,52\%, respectivamente.

Cannas et al. (2002) também observaram que a utilização de gordura protegida na produção de leite ovino proporcionou aumento tanto na produção de leite quanto no teor de gordura do leite, entretanto, isso foi muito mais rápido com o teor de gordura que na produção de leite.

De acordo com Oldhan (1984), a elevada porcentagem de gordura no leite de ovelhas sob suplementação com gordura protegida e das dieta com alto teor de proteína (22\%) pode ser explicada pelo aumento da mobilização do tecido adiposo desses animais no início da lactação, que pode elevar a proporção de ácidos graxos de cadeia longa na composição do leite (Palmquist \& Weiss, 1994).

O teor de proteína (Tabela 3) não diferiu entre os grupos controle e gordura protegida durante todo o período experimental. Resultados similares foram observados com Mckusick et al. (1999) em pesquisa com ovelhas suplementadas com gordura protegida (100 g/dia) durante o período de amamentação. Wu \& Huber (1994) também verificaram em vacas leiteiras que a probabilidade da suplementação lipídica afetar negativamente o teor proteico do leite é maior no início da lactação, em razão do balanço proteico negativo nessa fase, ou seja, há uma deficiência de aminoácidos para abastecer a alta síntese de proteína na glândula mamária.

Não foram observadas diferenças nos teores de lactose (Tabela 3), entre grupos controle e gordura protegida até a 6a semana de lactação. A partir daí os teores de lactose do

Tabela 2 - Produção de leite de ovelhas alimentadas com as dietas controle e com gordura protegida

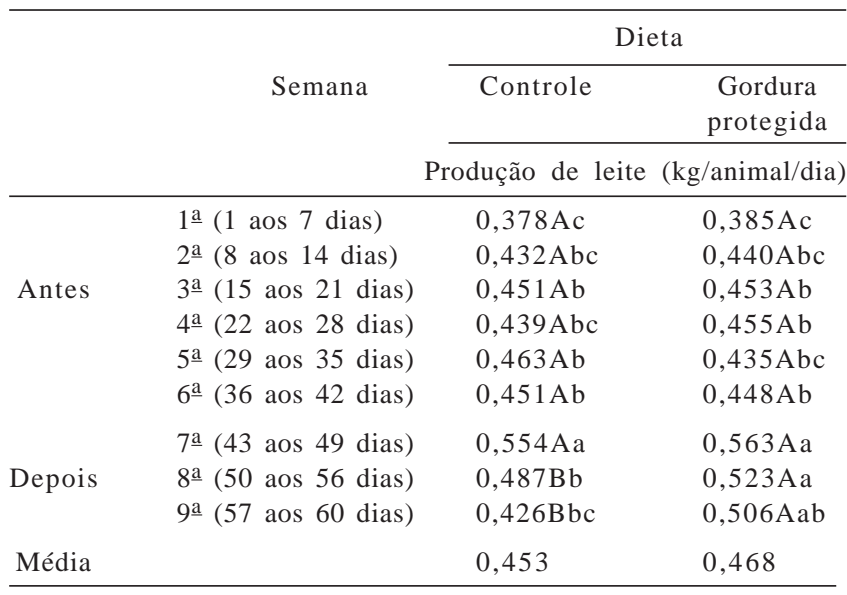

$\mathrm{CV}(\%)=22,09$.

Médias seguidas de letras iguais, maiúsculas nas colunas e minúsculas nas linhas, não diferem $(\mathrm{P}>0,05)$ entre si; pelo teste $\mathrm{t}$. 
grupo com 3,5\% de gordura protegida incorporada na dieta apresentaram maiores valores em relação ao grupo controle entre a 7므 e $8 \underline{\underline{a}}$ semana, mas voltaram a ser semelhantes na 9a semana. Isso mostra que os teores de lactose são inversamente proporcionais aos teores de gordura.

Os teores de sólidos totais (Tabela 3) apresentaram diferenças entre os grupos controle e gordura protegida apenas na 7aㅡ semana, discordando de relatos de Snowder \& Glimp (1991), que observaram maior teor de sólidos totais aos 28 dias e redução do mesmo, ao longo da lactação. Hassan (1995) obteve maiores teores de gordura e sólidos totais à medida que a produção de leite diminuiu ao longo da lactação.

Simos et al. (1996) obtiveram correlações negativas entre produção de leite e gordura; proteína e sólidos totais; gordura e lactose; sólidos totais e lactose. Nesse estudo, o pico de lactação ocorreu depois da desmama (após 45 dias) e, como teve duração de 60 dias, não foi possível estabilizar a porcentagem de gordura no grupo com gordura protegida, devido a um aumento na produção de leite dos animais desse grupo. Esses resultados diferem dos encontrados por Rotunno et al. (1998), que verificaram o efeito de três níveis de gordura protegida (0, 4 e 8\%) nas características do leite de ovelhas da raça Comisana, e registraram valores de 8,$98 ; 8,80 ; 9,21 \%$ de gordura e 6,39 ; 5,92; 5,98\%.

Caja \& Bocquier (1998) estudaram o efeito da nutrição na qualidade do leite de ovelhas utilizando dietas com diferentes níveis de gordura (1,55 e 1,65 Mcal EM), e não encontraram diferenças $(\mathrm{P}>0,05)$ nos teores de proteína e gordura na composição do leite.

Embora as correlações entre produção de leite e teores de gordura e proteína não tenham sido significativas, segundo Ochoa-Cordero et al. (2002) a produção de leite tem correlação negativa com a quantidade de sólidos totais, gordura e proteína e está diretamente ligada à quantidade de lactose. De acordo com Bencini \& Pulina (1997), esta relação é válida tanto quando se comparam as raças de alta e baixa produção, como em animais de maior ou menor produção de leite em um rebanho, até quando se consideram mesmo animal em vários estágios de lactação.

Não houve diferença quanto no teor de alfa e beta caseínas da 1a a 9a semana, logo, os teores não variaram durante toda a lactação.

Nos grupos controle e gordura protegida (35 g incorporado na dieta), foram observadas diferenças nos teores de alfa e beta-caseínas, que foram maiores no grupo controle. Isso mostra que a gordura protegida não teve efeito positivo para ambas caseínas (alfa e beta). Esse maior teor de caseína no grupo controle, ou seja, sem adição de gordura protegida, pode ser explicado pelo fato de que o teor de gordura pode influenciar o teor de caseína do leite, embora neste caso o teor de proteína não tenha diferido. Depeters \& Cant (1992) observaram correlação negativa entre gordura e proteína no leite. Casals et al. (1999), Gargouri et al. (1995), Pérez Alba et al. (1997) e Osuna et al. (1998), forneceram a ovelhas da raça Manchega dietas, com sais de cálcio de ácidos graxos, ou seja, gordura protegida, e observaram que os teores de gordura e sólidos totais no leite de ovelhas aumentaram significativamente e, na maioria dos casos, a proteína do leite diminuiu acentuadamente em toda a lactação. Nesse caso, a caseína do leite também diminuiu. Esses autores ressaltaram que o efeito dos sais de cálcio na diminuição da proteína do leite acentuou após a desmama, devido ao aumento da gordura do leite após essa fase (desmama), o que não ocorreu neste experimento. Ambrosoli et al. (1988) observaram que a alfa-caseína pode ser positivamente correlacionada à porcentagem de sólidos totais, proteína total e caseína.

Tabela 3 - Composição do leite de ovelhas alimentadas com uma dieta contendo gordura protegida

\begin{tabular}{|c|c|c|c|c|c|c|c|c|}
\hline \multirow[b]{3}{*}{ Semana } & \multicolumn{8}{|c|}{ Dieta } \\
\hline & \multicolumn{2}{|c|}{ Gordura $(59,20 \%)$} & \multicolumn{2}{|c|}{ Proteína $(11,92 \%)$} & \multicolumn{2}{|c|}{ Lactose $(9,27 \%)$} & \multicolumn{2}{|c|}{ Sólidos totais $(17,88 \%)$} \\
\hline & Controle & $\begin{array}{c}\text { Gordura } \\
\text { protegida }\end{array}$ & Controle & $\begin{array}{c}\text { Gordura } \\
\text { protegida }\end{array}$ & Controle & $\begin{array}{c}\text { Gordura } \\
\text { protegida }\end{array}$ & Controle & $\begin{array}{c}\text { Gordura } \\
\text { protegida }\end{array}$ \\
\hline $1 \underline{a}$ (1 aos 7 dias) & $4,64 \mathrm{Aa}$ & $3,05 \mathrm{Ac}$ & 4,88 & 4,92 & $4,97 \mathrm{Aa}$ & $4,91 \mathrm{Aa}$ & $16,00 \mathrm{Aa}$ & $14,33 \mathrm{Ab}$ \\
\hline $2^{\underline{a}}(8$ aos 14 dias $)$ & $1,63 \mathrm{Ab}$ & $1,85 \mathrm{Ac}$ & 4,62 & 4,74 & $4,90 \mathrm{Aa}$ & $5,09 \mathrm{Aa}$ & $12,46 \mathrm{Ac}$ & $13,04 \mathrm{Ad}$ \\
\hline 3a (15 aos 21 dias) & $1,03 \mathrm{Ab}$ & $1,77 \mathrm{Ac}$ & 4,75 & 5,03 & $5,02 \mathrm{Aa}$ & $5,24 \mathrm{Aa}$ & $12,13 \mathrm{Ac}$ & $13,50 \mathrm{Ac}$ \\
\hline 4 a $(22$ aos 28 dias $)$ & $1,55 \mathrm{Ab}$ & $2,20 \mathrm{Ac}$ & 4,81 & 4,95 & $4,86 \mathrm{Aa}$ & $5,08 \mathrm{Aa}$ & $12,57 \mathrm{Ac}$ & $13,67 \mathrm{Ac}$ \\
\hline 5a (29 aos 35 dias) & $1,99 \mathrm{Ab}$ & $2,26 \mathrm{Ac}$ & 4,82 & 5,01 & $4,94 \mathrm{Aa}$ & $4,98 \mathrm{Aa}$ & $13,13 \mathrm{Ab}$ & $13,69 \mathrm{Ac}$ \\
\hline 6므 (36 aos 42 dias) & $2,55 \mathrm{Ab}$ & $2,70 \mathrm{Ac}$ & 5,14 & 5,14 & $4,77 \mathrm{Aa}$ & $4,86 \mathrm{Aa}$ & $13,94 \mathrm{Ab}$ & $14,20 \mathrm{Ac}$ \\
\hline 7a (43 aos 49 dias) & $5,88 \mathrm{Aa}$ & $3,59 \mathrm{Bc}$ & 5,48 & 5,66 & $4,12 \mathrm{Bb}$ & $4,64 \mathrm{Ac}$ & $17,12 \mathrm{Aa}$ & $15,53 \mathrm{Bb}$ \\
\hline $8^{\text {a }}$ (50 aos 56 dias) & $7,08 \mathrm{Aa}$ & $5,37 \mathrm{Bb}$ & 5,49 & 5,44 & $3,67 \mathrm{Bc}$ & $4,14 \mathrm{Ad}$ & $17,90 \mathrm{Aa}$ & $16,56 \mathrm{Aa}$ \\
\hline 9a (57 aos 60 dias) & $7,21 \mathrm{Aa}$ & $7,47 \mathrm{Aa}$ & 5,15 & 5,32 & $3,65 \mathrm{Ab}$ & $3,90 \mathrm{Ad}$ & $17,69 \mathrm{Aa}$ & $18,33 \mathrm{Aa}$ \\
\hline Média & 3,73 & 3,36 & 5,02 & 5,14 & 4,55 & 4,76 & 14,77 & 14,76 \\
\hline
\end{tabular}

Médias seguidas de letras iguais, maiúsculas nas colunas e minúsculas nas linhas, não diferem $(\mathrm{P}>0,05)$ pelo teste t. 
Tabela 4 - Correlação entre produção de leite e teor de gordura, proteína, lactose e sólidos totais antes e após a desmama

\begin{tabular}{lcc}
\hline Constituinte do leite & Antes da desmama & Após a desmama \\
\hline Teor de gordura & 0,1812 & 0,0803 \\
Teor de proteína & $-0,2208$ & $-0,2127$ \\
Teor de lactose & $-0,0981$ & 0,3057 \\
Teor de sólidos totais & 0,0525 & 0,0793 \\
\hline
\end{tabular}

Não significativo $(\mathrm{P}>0,05)$ pelo teste $\mathrm{t}$.

Tabela 5 - Teores de alfa e de beta em função dos grupos controle e gordura protegida e semanas (Sem)

\begin{tabular}{|c|c|c|c|c|}
\hline \multirow[b]{3}{*}{ Semana } & \multicolumn{4}{|c|}{ Dieta } \\
\hline & \multicolumn{2}{|c|}{ Alfa (\%) } & \multicolumn{2}{|c|}{ Beta (\%) } \\
\hline & Controle & $\begin{array}{l}\text { Gordura } \\
\text { protegida }\end{array}$ & Controle & $\begin{array}{c}\text { Gordura } \\
\text { protegida }\end{array}$ \\
\hline $1^{\underline{a}}$ & $34,15 \mathrm{~A}$ & 19,47B & $28,76 \mathrm{~A}$ & $25,55 \mathrm{~B}$ \\
\hline $2 \underline{a}$ & $33,27 \mathrm{~A}$ & $19,85 \mathrm{~B}$ & $32,10 \mathrm{~A}$ & $25,93 \mathrm{~B}$ \\
\hline $3^{\underline{a}}$ & $29,99 \mathrm{~A}$ & $19,58 \mathrm{~B}$ & $30,90 \mathrm{~A}$ & $24,51 \mathrm{~B}$ \\
\hline $4^{\mathrm{a}}$ & $28,11 \mathrm{~A}$ & $16,85 \mathrm{~B}$ & $41,50 \mathrm{~A}$ & $25,17 \mathrm{~B}$ \\
\hline $5^{\underline{a}}$ & $19,66 \mathrm{~A}$ & $18,15 \mathrm{~B}$ & $29,44 \mathrm{~A}$ & $26,47 \mathrm{~B}$ \\
\hline $6^{\underline{a}}$ & $34,86 \mathrm{~A}$ & $17,13 \mathrm{~B}$ & $32,21 \mathrm{~A}$ & $26,30 \mathrm{~B}$ \\
\hline $7 \underline{a}$ & $34,90 \mathrm{~A}$ & $18,22 B$ & $32,56 \mathrm{~A}$ & $27,21 B$ \\
\hline $8^{\underline{a}}$ & $35,12 \mathrm{~A}$ & $18,56 \mathrm{~B}$ & $33,08 \mathrm{~A}$ & $28,04 \mathrm{~B}$ \\
\hline 9a & $35,57 \mathrm{~A}$ & $19,27 \mathrm{~B}$ & $33,48 \mathrm{~A}$ & $28,78 \mathrm{~B}$ \\
\hline Médias & 31,73 & 18,56 & 32,67 & 26,44 \\
\hline
\end{tabular}

CValfa (\%): 63,62; CVbeta (\%): 43,42.

Médias seguidas de letras iguais nas linhas não diferem $(P>0,05)$ entre si pelo teste $\mathrm{t}$.

Observa-se a localização das alfa (23 Kda) e beta (27 Kda) caseínas (Figura 3). A kappa-caseína não pôde ser observada, pois apresentou comigração com a beta-caseína devido ao seu peso molecular muito semelhante em leite de ovelhas. Já em vacas, isso não acontece. Esses resultados confirmam os encontrados por Dall'Olio et al. (1990), que observaram resultados semelhantes de eletroforese no leite de ovelhas, onde algumas bandas de beta- caseína migraram em algumas zonas que poderiam ser atribuídas como kappa-caseína.

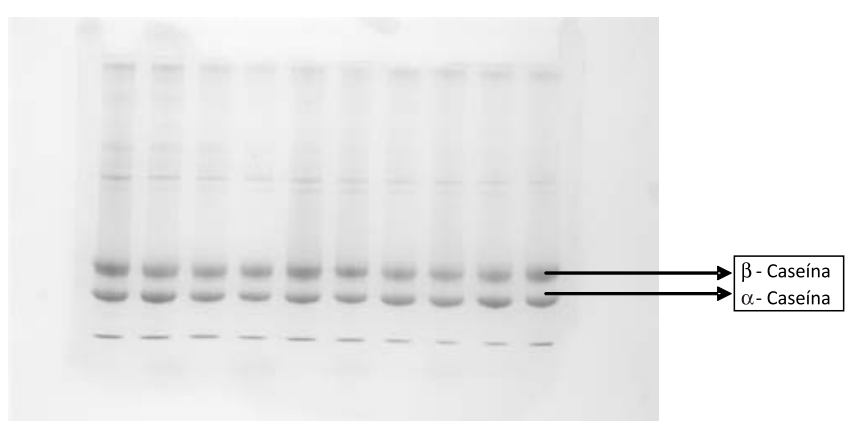

Figura 3 - Gel de eletroforese em SDS-PAGE (dodecil sulfato de sódio) de poliacrilamida a $10 \%$ de concentração no gel de separação e $4 \%$ de concentração no gel de empilhamento. Alfa-caseína - peso molecular de 23 Kda e beta-caseína - peso molecular de $27 \mathrm{Kda}$.

\section{Conclusões}

A adição de gordura protegida na dieta não altera a produção e composição centesimal do leite até o momento da desmama. Quando se administram 35 g de gordura protegida na dieta, ocorre diminuição nos teores de alfa e beta-caseínas.

\section{Agradecimentos}

À Doutora Simone Fernandes, FMVZ-UNESP-Botucatu, pelo auxílio na elaboração deste trabalho. Ao Mestrando Jeison Solano Spin, pela ajuda nas análises de leite.

\section{Referências}

AMBROSOLI, R.; STASIO, L.; MAZZOCCO, P. Content of alphas-casein and coagulation properties in goat milk. Journal of Dairy Science, v.71, p.24-28, 1998.

BENCINI, R., PULINA, G. The quality of sheep milk: a review. Wool Technology and Sheep Breeding, v.45, n.3, p.182-220, 1997.

BOCQUIER, F., CAJA, G. Production et composition du lait de brebis: effets de l'alimentation. INRA Production Animal, v.14, p.129-140, 2001.

BRUCKMAIER, R.M.; PAUL, G.; MAYER, G.P.H. et al. Machine milking of Ostfriesian and Lacaune dairy sheep: udder anatomy, milk ejection and milk characteristics. Journal of Dairy Science, v.64, p.163-172, 1997.

BRUCKMAIER, R.M.; BLUM, J.W. Oxytocin release and milk removal in ruminants. Journal of Dairy Science, v.81, p.939-949, 1998.

CAJA, G.; BOCQUIER, F. Effects of nutrition on ewe's milk quality. In: COOPERATIVE FAO-CIHEAM NETWORK ON SHEEP AND GOATS, Nutrition Subnetwork, 1998, Grignon. Proceedings... Grignon, 1998. p.1-16.

CAJA, G.; BOCQUIER, F. Effects of nutrition on the composition of sheep’s milk. Cahiers Options Méditerranéennes, v.52, p.5974, 2000.

CANNAS, A.A.; NUDDA, G.; PULINA, G. Nutritional strategies to improve lactation persistency in dairy ewes. In: GREAT LAKES DAIRY SHEEP SYMPOSIUM, 8., 2002, Wisconsin. Proceedings... Wisconsin: University of Wisconsin, 2002. p.17-59.

CASALS, R.; CAJA, G.; SUCH, X. et al. Lactational effects of calcium soap and undegraded intake protein on dairy ewes. Journal of Dairy Research, v.66, p.177-191, 1999.

CASU, S.; MARIE-ETANCELIN, C.; ROBERT-GRANIÉ, C. et al. Evolution during the productive life and individual variability of milk emission at machine milking in Sardinian $\mathrm{x}$ Lacaune back-cross ewes. Small Ruminant Research, v.75, p.7-16, 2008.

CHILLIARD, Y.; BOCQUIER F. Effects of fat supplementation on milk yield and composition in dairy goats and ewes. In: INTERNATIONAL SYMPOSIUM “LA QUALITA NELLE PRODUZINI DEI PICCOLI RUMINANTI”, 5., 1993, Varese. Proceedings... Varese: Camera di Commercio Industria Artigiano Agricultura di Varese, 1993. p.61-78.

CHURCH, D.C. Alimentos y alimentacion del ganado. Tomo Montevideo: Hemisferio Sur, 1984. 405p.

DALL'OLIO, S.; DAVOLI, R.; BOSI, P. Ricerche elettroforetiche delle proteine del latte nella razza ovina Sopra visana. Science and Technique Lattiero-Cassearia, v.40, p.186-194, 1990. 
DEGEN, A.A.; BENJAMIN, R.W. Milk intake and growth rate of Awassi lambs sucking ewes grazing on natural pasture in the semi-arid Negev. Animal Science, v.76, p.455-460, 2003.

DEPETERS, E.J.; CANT, J.P. Nutritional factors influencing the nitrogen composition of bovine milk: a review. Journal of Dairy Science, v.75, p.2043-2070, 1992.

GARGOURI, A.; CAJA G.; SUCH X. et al. Efectos de la utilización de lípidos protegidos en la alimentación de ovejas de ordeño en el sistema a media leche. ITEA Production Animal, v.16, p.720-722, 1995 (suppl.).

HALL, M.B.; HEREJK, C. Differences in yields of microbial crude protein from in vitro fermentation of carbohydrates. Journal of Dairy Science, v.84, p.2486-2493, 2001.

HAMES, B.D.; RICKWOOD, D. Gel electrophoresis of proteins. 2.ed. New York: Pas, 1990. 305p.

HASSAN, H.A. Effects of crossing and environmental factors on production and some constituents of milk in Ossimi and Saidi sheep and their crosses with Chios. Small Ruminant Research, v.18, p.165-172, 1995.

JENKINS, T.C.; PALMIQUIST, D.L. Effect of fatty acids or calcium soaps on rumen and total nutrient digestibily of dairy ratinos. Journal of Dairy Science, v.67, p.978-986, 1984.

KRONFELD, D.S.; DONOGHUE, S.; NAYLOR, J.M. et al. Metabolic effects protected tallow to dairy cows. Journal of Dairy Science, v.4, p.545-552, 1980.

LABUSSIERE, J. Importance, composition et signification des différentes fractions de lait obtenues successivement au cours de la traite mécanique des brebis. Animal Zootech, v.18, p.185-196, 1969

LABUSSIÈRE, J.; PÉTREQUIN, P. Relations entre l'aptitude à la traite des brebis et la perte de production laitière constatée au moment du sevrage. Anneles Zootech, v.18, p.5-15, 1969.

MARNET, P.G.; McKUSICK, B.C. Regulation of milk ejection and milkability in small ruminants. Livestook Production Science, v.70, p.125-133, 2001.

MARNET, P.G.; NEGRÃO, J.A. The effect of a mixed-management system on the release of oxytocin, prolactin, and cortisol in ewes during suckling and machine milking. Reproduction Nutrition Development, v.40, p.271-281, 2000.

MCKUSICK, B.C.; BERGER, Y.M.; THOMAS, D.L. Rumen protected bypass fat for dairy ewe commercial milk production. In: GREAT LAKES DAIRY SHEEP SYMPOSIUM, 5., 1999, Wisconsin. Proceedings... Wisconsin: University of Wisconsin, 1999. p.69-80

McKUSICK, B.C.; THOMAS, D.L.; BERGER, Y.M. et al. Effect of milking interval on alveolar versus cisternal milk accumulation and milk production and composition in dairy ewes. Journal of Dairy Science, v.85, p.2197-2206, 1999.
NATIONAL RESEARCH COUNCIL - NRC. Nutrient requirements of sheep anonymous. 6.ed. Washington, D.C.: National Academy Press, 1985. p.30-32.

OLDHAM, J.D. Protein-energy interrlationships in dairy cows. Journal of Dairy Science, v.67, p.1090-1114, 1984.

OSUNA, D.R.; CASALS, R.; CAJA, G. et al. Effects of feeding whole oilseeds to partially replace calcium soaps of fatty acids on dairy ewes intake and milk production and composition. Journal of Dairy Science, v.81 (Suppl. 1), p.302 (Abstr. 1179), 1998.

PALMQUIST, D.L., WEISS, W.P. Blood and hydrolyzed feather meals as sources of undegradable protein in high fat diets for cows in early lactation. Journal of Dairy Science, v.77, p.1630-1643, 1994

PÉREZ ALBA, L.M.; DE SOUZA, S.; PÉREZ, M. et al. Calcium soaps of olive fatty acids in the diets of Manchega dairy ewes: Effects on digestibility and production. Journal of Dairy Science, v.80, p.3316-3324, 1997.

RAMOS, P.R.R. Polimorfismo bioquímico de proteínas séricas do leite de vacas da raça holandês, puras por cruzamento, variedade malhada de preto. 1992. 131f. Tese (Doutorado em Ciências Biológicas) - Universidade do Estadual Paulista, Botucatu.

ROTTUNO, T.; SEVI, A.; DI CATERINA, R. et al. Effects of graded levels of dietary rumen-protected fat on milk characteristics of Comisana ewes. Small Ruminant Research, v.30, p.137-145, 1998.

SÁ, J.L.; OTTO DE SÁ, C. Produção de leite ovino: revisão. [2001]. Disponível em: <http://www.crisa.vet.br/publi_2001/ leite.htm>. Acesso em: 16/3/2008.

SÁ, C.O.; SIQUEIRA, E.R.; SÁ, J.L. et al. Influência do fotoperíodo no consumo alimentar, produção e composição do leite de ovelhas Bergamácia. Pesquisa Agropecuária Brasileira, v.40, n.6, p.601-608, 2005.

SIMOS, E.N.; NIKOLAOU, E.M.; ZOIOPOULOS, P.E. Yield, composition and certain physicochemical characteristics of milk of the Epirus mountain sheep breed. Small Ruminant Research, v.20, p.67-74, 1996.

SNOWDER, G.D.; GLIMP, H.A. Influence of breed, number of suckling lambs, and stage of lactation on ewe milk production and lamb growth under range conditions. Journal Animal Science, v.50, p.597-603, 1991

STELL, R.G.D.; TORRIE, J.H. Principles and procedures of statistic. A biometrical approach. 2.ed. New York: Mc Graw-Hill, 1980. 633p.

UNIVERSIDADE FEDERAL DE VIÇOSA - UFV. Sistema de análises estatísticas e genéticas - SAEG. Versão 9.0 Viçosa, MG, 2000, 150p. (Manual do usuário).

WU, Z.; HUBER, J.T. Relationship between dietary fat supplementation and milk protein concentration in lactating cows: a review. Livestock Production Science, v.39, p.141-155, 1994 